La chambre de l'enfant, de J. M. Benet, Maison des Initiatives Etudiantes,

2004 (Pere Arquillué e Emma Vilarasau, Albert Capdevila).

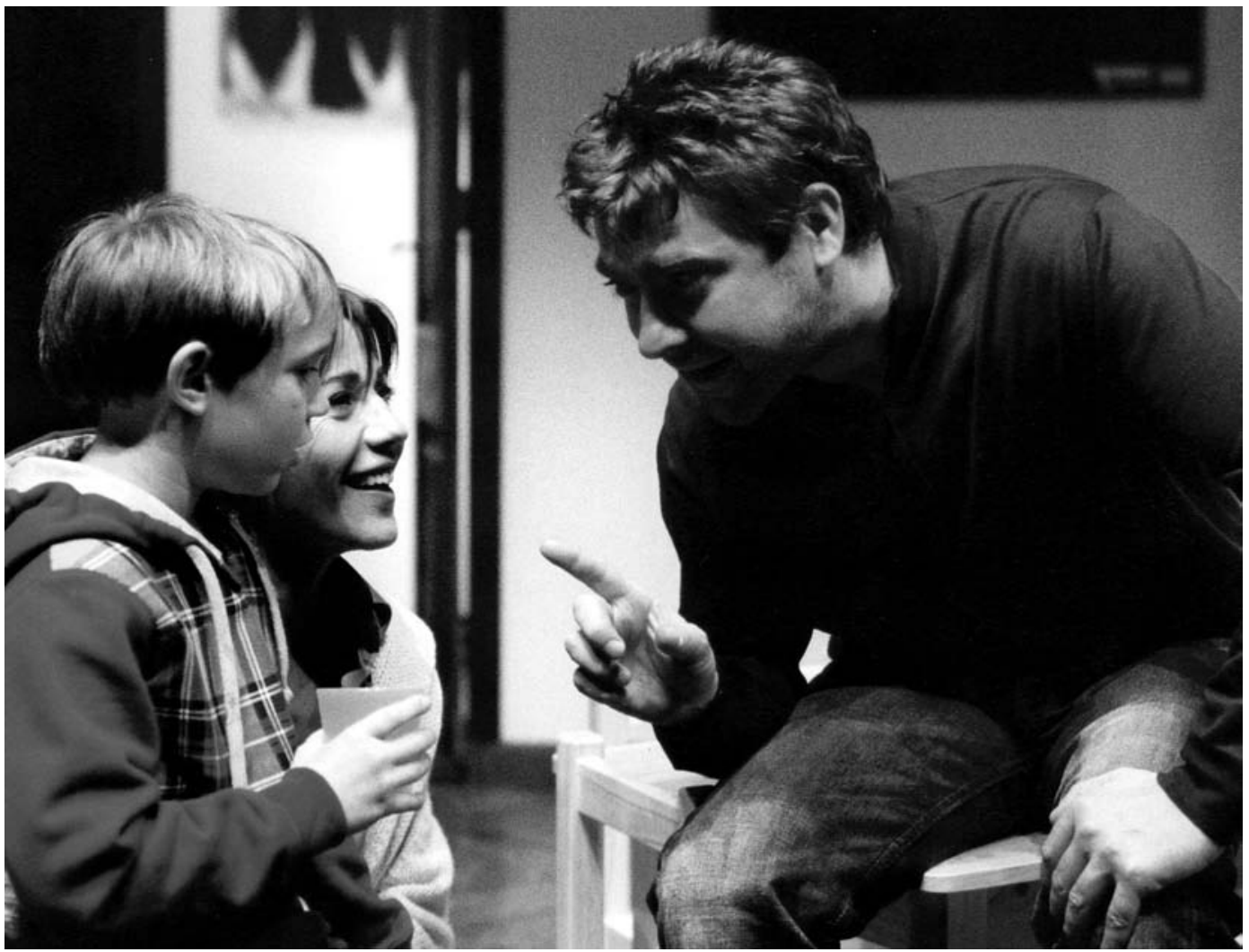

\title{
Teatro catalão em Paris
}

\section{Francesc Massip ${ }^{1}$}

Entre Novembro de 2004 e o início de 2005 decorreu em Paris uma importante jornada dedicada a três dramaturgos representando três gerações distintas do teatro catalão contemporâneo: Jordi Pere Cerdà (Sallagosa, 1920), Josep M. Benet i Jornet (Barcelona, 1940) e Beth Escudé i Gallés (Barcelona, 1963). Três estilos e trajectos autorais que interrogam de modo diverso a evolução da escrita dramática, as suas formas, os seus compromissos durante o franquismo o pós-franquismo e os dias de hoje.

0 programa, coordenado por Irène Sadowska-Guillon foi organizado por Hispanité Explorations, com a colaboração do Centre d'Études Catalanes da Universidade de Paris IV dirigido por Denise Boyer, e com o apoio dos Institutos Ramon Llull e Cervantes. 0 ciclo incluiu a representação de quatro peças: Fugaces (Fugaz), de Benet i Jornet, traduzida por Michel Azama e encenada por Hervé Petit com a Compagnie La Traverse (Théâtre L'Étoile du Nord) Quatre femmes et le soleil (Quatro mulheres e o sol), de J.P.Cerdà, traduzida por Antoni e Elena Cayrol, sob a batuta de Neus Vila à frente da Compagnie du Sarment (Centre d'Animation les Halles); La chambre de l'enfant (O quarto do filho), de Benet, traduzida por Josep M.Vidal Turon e adaptada por Hervé Petit (Maison des Initiatives Etudiantes) e Entre chien et loup (Entre cõo e lobo), d'Escudé, traduzida por Isabelle Bres e encenada por Neus Vila (Forum des Halles). Os três autores participaram também na mesa redonda sobre A evolução da escrita teatral através de três gerações de autores, que teve lugar no Centre d'Estudis Catalans, moderada pelo autor destas linhas.
Como reconheceram os próprios organizadores, a criação teatral catalã tem experimentado uma grande projecção internacional, em especial graças a grupos como Els Comediants ou La Fura dels Baus que propunham uma tipologia de espectáculo urbano, baseado em elementos visuais e sonoros e de onde o texto estava praticamente ausente, facto que permitia transcender as fronteiras linguísticas. Por seu turno, à dramaturgia textual catalã custou-Ihe mais impor-se: por um lado, devido ao assédio que a nossa língua sofreu e sofre, por parte dos Estados monolíngues e da Europa dos grandes com que a flamejante Constituição nos proscreve e humilha até extremos de tal forma antidemocráticos que aconselham um voto contra a aprovação deste regime legal injusto; mas também pelo escasso interesse que os profissionais de teatro do país dispensaram aos textos autóctones, $\mathrm{e}$ não por falta de qualidade, antes por uma estranha mistura de autofobia, falta de ambição e estreiteza de vistas, complexos que se têm vindo a superar, não sem dificuldades, nas últimas décadas, em parte graças a um maior suporte institucional e ao impulso de novos dramaturgos que lutaram para levar à cena os seus próprios textos.

Uma leitura política?

Os três autores escolhidos pertencem não só a gerações distintas, como também a contextos histórico-sociais diversos, sinal indicador da riqueza e variedade do teatro de expressão catalã. 

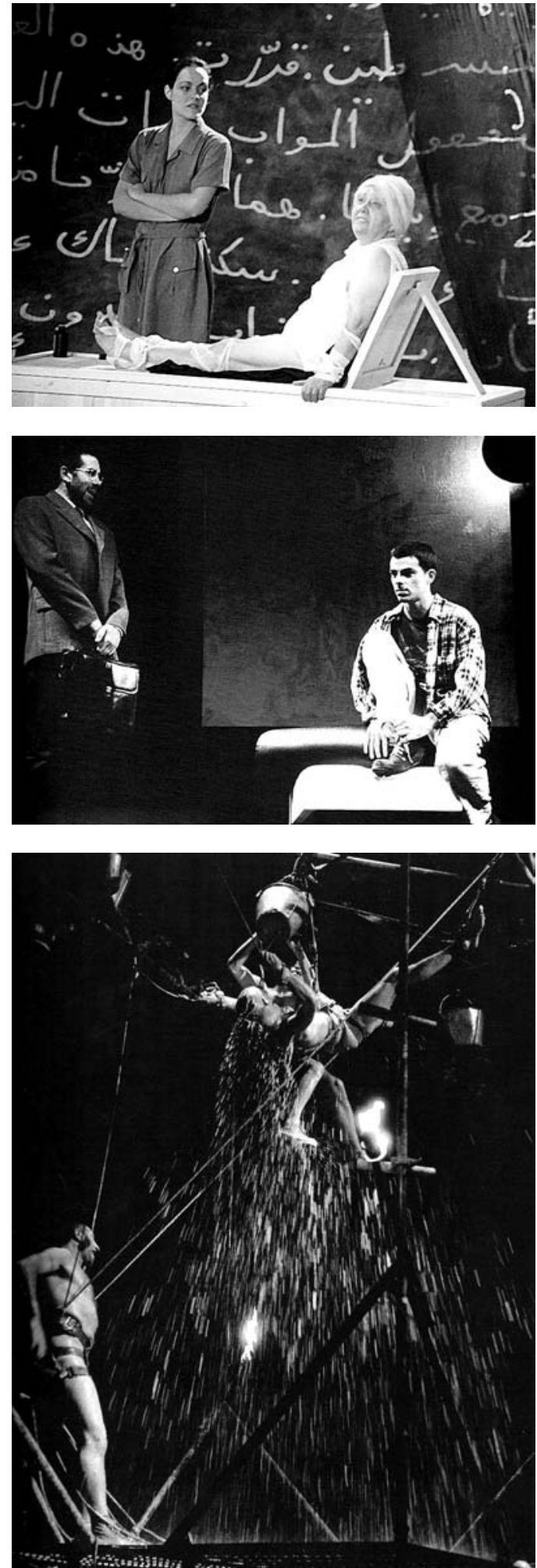

Jordi Pere Cerdà, pseudónimo de Antoni Cayrol, é o gigante do Norte da Catalunha, talhante na Alta Cerdanya, livreiro em Perpignan, escritor autodidacta e diamantino, com uma extensa e sólida produção literária, que abarca todos os géneros (poesia, romance, memórias) incluindo o teatro: ao lado de quatro sainetes escritos na sua juventude representados em Sallagosa em 1941, publicou a Obra teatral (Barcino 1980) com cinco peças escritas durante a década de 50; a última, Quatre dones i el sol (Quatro mulheres e o sol), estreou-se no Romea em 1964, com uma montagem de cunho naturalista que não se conjuga com as pulsões tchekovianas da peça, que desabrochou na cuidada encenação efectuada no mesmo local por Ramon Simó (1990), na altura ainda Centre Dramàtic de la Generalitat. É uma obra que, aliás, vai muito além da sua consideração como "drama rural", como tem sido frequentemente etiquetado. Com efeito, ainda que uma leitura superficial possa levar a essa ideia, não se trata, de todo, de um drama rural. Cerdà observa e desnuda o pregão da alma humana e fá-la falar, com uns diálogos de elevada intensidade expressiva, pela boca de quatro mulheres que, situadas entre a espada da repressão interior e a parede de pedra viva que uma determinada visão do mundo configurou ao longo de gerações, roçam a tragédia. E isto dentro de um cenário entendido como uma prisão pelas personagens que o habitam, um toque pirandelliano de grande modernidade: quatro personagens que, com as asas feridas ou recortadas, esvoaçam atabalhoadamente, chocando contra as grades da gaiola que constitui a própria cena.

Temos Margarida, a matriarca que tudo vigia, a senhora que, qual "louva-a-deus", devorou o conceito de homem, que nega a sua própria feminilidade e afasta as demais mulheres do contacto com o macho. Nos antípodas está a sua cunhada Vicenta, que não renunciou ao fogo da paixão e que representa a dissidência (com a ordem estabelecida por Margarida), a qual tenta transmitir às mulheres mais jovens: Bepa, a nora, esposa do filho de Margarida, que foi feito prisioneiro há três anos na Alemanha, e Adriana, a filha adolescente de Margarida, raparigas jovens que se debatem entre os dois modelos em conflito, em busca de uma liberdade inalcançável como um raio de sol. Para além da leitura trágica da condição humana, forçada a balançar entre o amor e a morte, poderia também fazer-se uma leitura política, em que a mãe emula o poder e representa o Estado, a autoridade ausente e distante, num país e numa cultura que sofrem desde há mais de três séculos o desapossamento estatal, a falta de "pátria". Vicenta é a memória do passado, a consciência de liberdade, a "mátria" negada, silenciada e submissa e que, depois de ter ocultado a profunda injustiça que sofreu durante toda a vida, só na morte é que encontra a escapatória. Bepa representa (ou aparenta?) a submissão a quem manda, talvez para herdar o cargo de administrador delegado, e defronta-se com Adriana que encarna um futuro solar desejoso de independência.

\section{A tragédia do efémero}

A tensão entre Eros e Thanatos marca também as linhas de força da obra de Benet i Jornet, Fugaç (Fugaz), estreada no Romea em 1994 sob a direcção de Rosa M. Sardà, cuja versão francesa, devida ao também dramaturgo Michel Azama, esteve em cena em Paris no Théâtre L'Étoile du Nord nos meses de Novembro e Dezembro passados.

Como é sabido, Benet i Jornet, com uma quarentena de obras produzidas, é o autor mais conhecido e difundido dos veteranos do teatro catalão. Foi o mais destacado

\section{Entre chien et loup \\ de Beth Escudé, \\ enc. Neus Vila, \\ Forum des Halles, 2004.}

Testament,

de Benet i Jornet,

enc. Sergi Belbel,

Focus Prod., 1997 (Lluis Soler e David Selvas), fot. Pilar Aymerich.

\section{Suz/0/Suz,}

La Fura dels Baús, 1991, fot. Dona Ann McAdams. 
representante da denominada "Generació dels Premis Sagarra"2 dos quais foi o primeiro galardoado com D'una vella, coneguda olor (De um cheiro antigo e familiar, 1963), expoente de um teatro realista que tanto se identificava com o estilo de Tennessee Williams como com o de Buero Vallejo. 0 dramaturgo sempre se caracterizou pelo esforço de adaptar as suas formas expressivas aos novos tempos, às novas tendências e aos novos conteúdos que o contexto reclama; uma obsessão que é o resultado do seu objectivo primordial: comunicar com as pessoas. Assim, assimila a influência do teatro épico e recorre ao distanciamento brechtiano em Mar i Jofré (O mar e Jofré, 1966-68) ou em Berenàveu a les fosques (Lanchavam no escuro, 1971), e exaspera o realismo, fecunda-o de simbolismo em Revolta de Bruixes (Revolta de bruxas, 1975). Com Desig (Desejo, 1989) abre uma nova etapa na qual assimila e filtra, no seu peculiar alambique, as novas tendências dramatúrgicas, desde Samuel Beckett até Thomas Bernhard passando por Harold Pinter. Esta versatilidade formal de Benet nunca ocultou, porém, determinadas obsessões que configuram as suas constantes mais pessoais: o tema da herança, a transmissão do saber e dos ideais, a possibilidade de sobrevivência; o tema da memória, da erosão do tempo, da morte e da transcendência; o tema do compromisso do indivíduo em sociedade, da procura de um sentido para a vida; o tema da precariedade do amor, do desejo inalcançável, da dor gratuita, da infelicidade. São inquietudes que surgem em Fugaç e em E.R. (1994), em Testament (Testamento, 1997), El gos del tinent (0 cão do tenente, 1999) ou Olors (Cheiros, 2000), obras com as quais Benet consolidou definitivamente o seu estatuto de ponto de referência iniludivel da actual dramaturgia catalã. Para tal contribuiu também, e de forma decisiva, a sua incursão televisiva que, a partir de 1976, renovou o panorama audiovisual catalão, e a sua presença na cena internacional, com duas dezenas de obras traduzidas. L'habitació del nen (0 quarto do filho), estreada no Lliure em 2003 e, presentemente, a última obra de Benet foi apresentada na Maison des Initiatives Etudiantes com tradução de Josep M.Vidal (La chambre de l'enfant).

Assim, em Fugaçé o pai que parece ter tudo sob controlo: homem sensato mas cobarde, debate-se entre a chama do amor e a frialdade do tabu, espartilhado pelas convenções e inércias culturais que traçam barreiras intransponiveis, como o incesto, que quando se transgridem aproximam o rebelde da peripécia trágica (recorde-se

${ }^{2}$ N. dos T.: Geração dos Prémios Sagarra.

${ }^{3}$ Tradução literal da frase idiomática citada no titulo.

Na tradução francesa

ficou Entre chien et loup (Entre cão e lobo).

${ }^{4} \mathrm{~N}$ dos T.: Novos Autores Cata|ães.
Édipo). A intima cumplicidade amorosa entre pai e filha esvai-se quando aquele toma consciência da fugacidade do desejo e das ilusões humanas, da dor que produz o facto de viver e de amar, e finalmente, esmagado por tanta lucidez e incapaz de ser livre, acaba por negar-se a felicidade a si próprio e, em consequência, aos seus.

El color de gos quan fuig ( $A$ cor do cão quando foge $e^{3}$ ), de Beth Escudé, estreou-se na Sala Beckett de Barcelona em 1997 no âmbito do ciclo "Nous Autors Catalans" Escudé formou-se no Institut del Teatre de Barcelona onde se especializou em Dramaturgia e Encenação e onde actualmente ensina. Combina frequentemente os dois papéis de dramaturga e encenadora, especialmente nas primeiras obras como $E l$ destí de les violetes ( 0 destino das violetas, 1995), El pensament per enemic (O pensamento como inimigo, 1996) ou El color del gos quan fuig (1997), ainda que, mais recentemente, tenha mostrado maior preferência pela escrita, e talvez por isso é que ainda não foram encenadas as suas últimas peças: Beats (Prémio Crèdit Andorra, 2000 e Prémio Per Humor a l'Art 2002) uma comédia extravagante que aguarda ser encenada por El Tricicle, e Les nenes mortes no creixen (As meninas mortas não crescem) (Prémio Joaquim Bartrina, 2001) na minha opinião, a melhor peça da autora, da qual se fez apenas uma leitura dramatizada. Forma parte da última fornada do Projecto T6 (2004-2005), uma espécie de bolsa que o Teatre Nacional de Catalunya (TNC) oferece à nova dramaturgia catalã, com o objectivo de promover a criação de textos em estreita relação com o processo de montagem cénica.

Em El color del gos quan fuig/Entre chien et loup as rédeas do diálogo regem-se por um duo de sogra e nora que compartem o fardo de uma convivência feita de amoródio, que abraçam as censuras com as recordações de bem-estar, a tragédia com a generosidade, e recordam as histórias saqueadas ao longo das suas vidas, justamente quando estão a ponto de mudar a anciã para a solidão do hospício ou para a morada final. Como pano de fundo, ressoam relatos bíblicos (livro de Rute) e míticos (Hécuba, Andrómaca), para desembocar numa fábula de invenção própria na qual a jovem Draupadi ajuda a anciã Xandra a morrer, numa terna cerimónia de eutanásia cúmplice.

Assim, os três dramaturgos apresentam-nos, sob o fundo comum de um conflito inter-geracional (mãe/pai/sogra versus filhas e noras), o implacável pêndulo que percorre a vida entre o amor e a extinção, entre o desejo e o desengano, entre a esperança iludida e uma impenetrável frustração que vai mais além dos indivíduos, para implicar todo o género humano.

Se Escudé faz da morte um último acto de afecto, num canto ao amor transcendit, Benet, depois de elogiar a ingenuidade e o egoísmo, lança os protagonistas no amor cancellat, enquanto que Cerdà, depois de submergir as suas personagens num clima de tédio tchekoviano, agitaas na evidência do amor frustrat, de impossivel concretização.

Três visões pertinentes e desassombradas da árida passagem dos humanos pelos caminhos de uma existência prenhe de escuridão, salpicada ao longe por pirilampos, poeira de estrelas cadentes ou raios de sol furtivos que não aquecem. As noites invernais de Paris puderam contemplar, assim, quais três explosões de luz, estas três amostras significativas do teatro catalão actual. 